\title{
Kiakhta et la mondialisation (Kiakhta sur Internet et Internet à Kiakhta en 2003)
}

Kiakhta and Globalisation (Kiakhta on the Internet and the Internet in Kiakhta in 2003)

\section{Kirill Titaev}

\section{(2) OpenEdition}

\section{Journals}

Édition électronique

URL : https://journals.openedition.org/emscat/1229

DOI : $10.4000 /$ emscat.1229

ISSN : 2101-0013

Éditeur

Centre d'Etudes Mongoles \& Sibériennes / École Pratique des Hautes Études

Édition imprimée

Date de publication : 1 décembre 2008

Pagination : 409-417

ISBN : 978-2-9518888-4-5

ISSN : 0766-5075

Référence électronique

Kirill Titaev, « Kiakhta et la mondialisation (Kiakhta sur Internet et Internet à Kiakhta en 2003) », Études mongoles et sibériennes, centrasiatiques et tibétaines [En ligne], 38-39 | 2008, mis en ligne le 17 mars 2009, consulté le 13 juillet 2021. URL : http://journals.openedition.org/emscat/1229 ; DOI : https:// doi.org/10.4000/emscat.1229

Ce document a été généré automatiquement le 13 juillet 2021.

(c) Tous droits réservés 


\section{Kiakhta et la mondialisation (Kiakhta sur Internet et Internet à Kiakhta en 2003)}

Kiakhta and Globalisation (Kiakhta on the Internet and the Internet in Kiakhta in 2003)

Kirill Titaev

\section{RÉSUMÉS}

Cet article analyse la représentation sur Internet de la zone frontalière russo-mongole de Kiakhta. Il met en lumière les tendances principales à l'œuvre dans la constitution de l'image de Kiakhta sur l'Internet: la ville apparaît comme refermée sur elle-même. En outre, l'article rend compte de l'usage d'Internet à Kiakhta.

This paper analyzes the Internet representation of the Russian/Mongolian borderland of Kiakhta. It sheds light on the main trends of this image on the Internet: the city appears closed onto itself. Moreover, the second half of this paper, which is based on qualitative sociological methods, explains the Internet usage in Kiahta, where there are very few computers. 
INDEX

Mots-clés : Internet, Kiakhta, Maimacheng, Route du thé, Troitkosavsk

Index géographique : Chine, Cisbaïkalie, Djoungarie, Mongolie, Russie, Sibérie, Transbaïkalie

Keywords : Internet, Kiakhta, Maimacheng, Tea Road, Troitkosavsk

Thèmes : frontières, histoire

nomsmotscles Bouriate, Chinois, Oirate, Russe

\section{AUTEUR}

\section{KIRILL TITAEV}

Kirill Titaev est doctorant en sociologie à l'Université européenne de Saint-Pétersbourg. Il est chercheur au Centre des recherches sociales indépendantes et de l'éducation (Irkoutsk). Il s'intéresse à l'économie informelle, à la sociologie de l'éducation et à la sociologie de l'Internet. titaev-k@yandex.ru 